\title{
Climate Change and Common but Differentiated Responsibilities for the Ocean
}

\begin{abstract}
Robin Kundis Craig*
Nations' impacts on the ocean and their impacts on climate change are linked, especially given the synergistic interactions among these impacts on the two largest global commons - the atmosphere and the ocean. This article argues that climate change mitigation law, as represented internationally by the United Nations Framework Convention on Climate Change and its follow-on agreements, can better reflect nations' broader Common but Differentiated Responsibilities (CBDR) by taking ocean impacts into account-in particular, contributions to ocean acidification and to marine fishing.
\end{abstract}

\section{Introduction}

Large parts of the Great Barrier Reef in Australia are, by most accounts, dying. In 2015 and 2016, the reef experienced unprecedented coral bleaching, a phenomenon that occurs when coral polyps expel their symbiotic algae (zooxanthellae) in response to excessively warm waters. ${ }^{1}$ Less than nine percent of the reef escaped bleaching, ${ }^{2}$ and, in the areas most affected, up to 83 percent of the coral died. ${ }^{3}$ The Australian Expert Panel overseeing the reef 'concluded that coral bleaching since early 2016 has changed the Reef fundamentally'; while 'hope still remains for maintaining ecological function over the coming decades,' the members agreed that 'substantial areas of the Great Barrier Reef and the surrounding ecosystems are experiencing major long-term damage which may be irreversible unless action is taken now. ${ }^{4}$ The panel's most urgent recommendation was to reduce greenhouse gas emission to curb climate change impacts, but it also noted that the long-term sustainability plan should be modified to pursue 'a sustainable, functional Reef in the face of emerging cumulative impacts, ${ }^{5}$ which include, besides climate change, water quality problems and fishing. ${ }^{6}$

Coral reefs are the marine ecosystems on the front line of climate change and its 'evil twin,' ocean acidification. However, as the scientists watching the Great Barrier Reef have emphasised, cumulative and synergistic impacts in the ocean, including fishing, pose exacerbated and unexpectedly fast-moving threats $^{7}$ to all marine ecosystems, threatening the largest global commons-and the largest carbon sink —on the planet.

Nevertheless, as a legal matter, the ocean has so far been of limited concern in climate change mitigation negotiations, treaties, and other agreements. This article argues that a marine-centric view of climate change demands a far more nuanced calculation of nations' Common but Differentiated Respon-
DOI: $10.21552 /$ cclr/2017/4/8

* Robin Kundis Craig is the James I Farr Presidential Endowed Professor of Law, University of Utah SJ Quinney College of Law, Salt Lake City, UT. She is thankful to the Quinney Foundation for its continued support of her scholarship. This research was also made possible, in part, through generous support from the Albert and Elaine Borchard Fund for Faculty Excellence. For correspondence: <robin.craig@law.utah.edu>

1 Terry P Hughes et al, 'Global warming and recurrent mass bleaching of corals' (2017) 543 Nature 373.

2 ibid.

3 Damien Cave and Justin Gillis, 'Large Sections of Australia's Great Reef Are Now Dead, Scientists Find' The New York Times (New
York, 15 March 2017) <https://www.nytimes.com/2017/03/15/ science/great-barrier-reef-coral-climate-change-dieoff.html ?mcubz=2> accessed 17 July 2017.

4 Australian and Queensland Governments, 'Reef 2050 Plan: Independent Expert Panel Communiqué 1 (5 May 2017) <https:// www.environment.gov.au/system/files/pages/abffod5e-b94d-4495 -b79b-90dc52274f69/files/expert-panel-communique-5may2017 .pdf $>$ accessed 17 July 2017.

5 ibid.

6 Hughes et al (n 1) 373.

7 For example, the devastation of the Great Barrier Reef came at least 30 years earlier than scientists were expecting, in large part because of the confluence of climate change warming and an especially warm El Niño event. Cave and Gillis (n 3). 
sibilities (CBDR) in responding to climate change to account for contributions to ocean acidification and for marine fishing. It begins in Part II with a short overview of climate change's impacts on the ocean and ocean acidification, including their synergistic impacts with each other and with other anthropogenic stressors to the marine environment. Part III then examines the role that CBDR currently plays in international climate change law, focusing on the United Nations Framework Convention on Climate Change (UNFCCC) $)^{8}$ and its follow-on agreements. It also makes the case that nations' differential contributions to marine degradation should lead to: (1) a legal distinction between carbon dioxide emissions and emissions of other greenhouse gases; and (2) a legal recognition that marine fishing both exacerbates climate change and increases adaptation stress. The article concludes with practical examples of how this new marine-oriented CBDR could be assessed, using information about national emissions and fishing activity that is already collected.

\section{Climate Change, Ocean Acidification, and the Ocean}

Many facets of the ocean both reflect and affect the processes of climate change. ${ }^{9}$ This part explores three aspects of the relationships among climate change, ocean acidification, and the ocean: the impacts of greenhouse gas emissions on the ocean itself; the implications of those impacts for marine ecosystems and human well-being; and the contributions of human marine activities to climate change.

8 United Nations Framework Convention on Climate Change, 'First steps to a safer future: Introducing The United Nations Framework Convention on Climate Change' (UNFCCC) <http://unfccc.int/ essential_background/convention/items/6036.php $>$ accessed 17 July 2017.

9 Robin Kundis Craig, 'The Atmosphere, the Oceans, Climate, and Ecosystem Services' in William H Rodgers, Jr, M Robinson-Dorn, JK Barcelos, and AT Moritz (eds), Climate Change: A Reader (Carolina Academic Press 2011).

10 National Aeronautics and Space Administration (NASA), 'What Are Climate and Climate Change?' (26 October 2011, as updated 16 September 2015) <https://www.nasa.gov/audience/forstudents/ 5-8/features/nasa-knows/what-is-climate-change-58.html > accessed 17 July 2017.

11 For a more expansive discussion of ocean acidification, see Robin Kundis Craig, 'Dealing with Ocean Acidification: The Problem, the Clean Water Act, and State and Regional Approaches' (2015) 90 Wash L Rev 1583 1589-1602.

\section{The Impacts of Anthropogenic Greenhouse Gas Emissions on the Ocean}

Anthropogenic additions of greenhouse gases into the atmosphere have five main impacts on the ocean. All but one of these impacts derive primarily from global warming - that is, the increase in global average temperature as a result of the atmosphere trapping more heat. ${ }^{10}$ The last impact results from an independent chemical reaction of carbon dioxide in seawater and is known as ocean acidification. ${ }^{11}$

First, the ocean absorbs much of the excess heat that global warming is producing. According to the Intergovernmental Panel on Climate Change (IPCC) in its 2014 report, ocean warming accounts 'for more than $90 \%$ of the energy accumulated between 1971 and 2010 (high confidence),' compared to 'only about $1 \%$ stored in the atmosphere. ${ }^{12}$ While ocean warming is greatest at the surface, it now extends at least 3000 meters down, probably reaching the bottom of most parts of the ocean. ${ }^{13}$ The IPCC also projects that ocean warming will continue throughout the 21st century. ${ }^{14}$

Warming of the oceans has a number of follow-on consequences. For example, ocean currents are changing. ${ }^{15}$ Changing currents affect weather patterns, ${ }^{16}$ fish stocks, and marine ecosystems more generally. Arctic sea ice will continue to melt, ${ }^{17}$ and icefree Arctic Ocean summers are likely by mid-century, ${ }^{18}$ potentially opening that ocean to shipping and commerce, including fishing.

Ocean warming also affects all levels of marine biodiversity and ecosystem function, from micro-organ-

12 Intergovernmental Panel on Climate Change, 'Climate Change 2014: Synthesis Report' (2014) 40 [hereinafter '2014 IPCC Synthesis Report']. According to the International Union for the Conservation of Nature (IUCN), 'More than $93 \%$ of the enhanced heating since the 1970s due to the greenhouse effect and other human activities has been absorbed by the ocean, even affecting the deep ocean.' Daniel Laffoley and JM Baxter (eds), Explaining Ocean Warming: Causes, Scale, Effects, and Consequences International Union for the Conservation of Nature (IUCN) (2016) 17 <https://portals.iucn.org/library/node/46254> accessed 17 July 2017 [hereinafter 2016 IUCN Ocean Warming Report].

132014 IPCC Synthesis Report (n 12) 40.

14 ibid 60.

15 ibid.

162016 IUCN Ocean Warming Report (n 12) 359.

172014 IPCC Synthesis Report (n 12) 60.

182016 IUCN Ocean Warming Report (n 12) 323. 
isms ${ }^{19}$ and plankton ${ }^{20}$ to sea turtles ${ }^{21}$ and marine mammals. ${ }^{22}$ In addition, ocean warming is negatively affecting most marine and coastal plants, including seaweeds, ${ }^{23}$ seagrasses, ${ }^{24}$ and mangroves ${ }^{25}$ — which, as discussed below, can itself accelerate climate change. A variety of marine ecosystems, as well, are changing in response to ocean warming, including intertidal rocky habitats, ${ }^{26}$ coral reefs, ${ }^{27}$ and deep sea/open ocean ecosystems. ${ }^{28}$ 'Observation so far suggest fishes have shifted their ranges by 1os to 100s of [kilometers] as the ocean has warmed,' and '[o]cean warming is modifying the seasonality of occurrence of biological events such as spawning and migration. This affects fish because of mismatch in the timing of availability of their prey. $^{.29}$ In the Arctic, '[s]ub-Arctic species will expand northward and compete with the Arctic species. ${ }^{30}$

Second, the salinity of the ocean is changing in response to both increased evaporation and more runoff and ice melt. According to the IPCC, '[i]t is very likely that regions of high surface salinity, where evaporation dominates, have become more saline, while regions of low salinity, where precipitation dominates, have become fresher since the 1950s. ${ }^{31}$

Salinity changes affect species survival and biodiversity: Species are generally adapted to live within certain salinity ranges, and salt concentrations outside that range will affect growth, reproduction, and survival. ${ }^{32}$ However, changes in salinity can also affect sea level rise, and 'regional sea-level changes due to salinity were much larger than had been previous-

9 ibid 57

20 ibid 75.

21 ibid 289.

2 ibid 303

3 ibid 88.

4 ibid 121.

25 ibid 135

26 ibid 147

27 ibid 178

28 ibid 199

29 ibid 240

30 ibid 322

312014 IPCC Synthesis Report (n 12) 40.

32 National Oceanic and Atmospheric Administration, 'NOAA Ocean Service Education: Salinity' (as revised 6 July 2017) $<$ https://oceanservice.noaa.gov/education/kits/estuaries/media/ supp_estuar10c_salinity.html> accessed 17 July 2017.

33 Jon Cartwright, 'Salinity changes affect sea level more than scientists thought' (Environmental Research News 9 February 2015) <http://environmentalresearchweb.org/cws/article/news/ 60135> accessed 17 July 2017. ly assumed-up to one-quarter of the size of the coincident sea-level changes due to temperature variations and the resulting thermal expansion of the water. $^{33}$ The effect goes both ways: 'Whereas in the Pacific Ocean a freshening, or salinity reduction, has led to a density drop that augments thermally driven sea-level rise, in the Atlantic an increase in salinity has boosted density, acting against the sea-level rise due to temperature.' 34

Third, as a result of warming and increased stratification of the ocean, the ocean's dissolved oxygen content is decreasing. ${ }^{35}$ This phenomenon appears to be most significant for the tropics, although it is occurring in many coastal and open ocean regions. ${ }^{36}$ Recent research indicates that the ocean's overall dissolved oxygen content has decreased by over two percent since 1960, with some areas near mid-depth oxygen-minimum zones losing four percent per decade over the same period. ${ }^{37}$

Decreased oxygen is referred to as 'hypoxia,' and the ocean's hypoxic zones are increasing and expanding. ${ }^{38}$ Non-air-breathing marine animals (fish, shellfish, zooplankton, but not marine mammals or sea turtles) need dissolved oxygen to survive, and so hypoxia represents a threat to ocean nutrient cycles, marine biodiversity, fisheries, and coastal economies. ${ }^{39}$ At the extreme, hypoxia creates ocean 'dead zones' where no animal life can exist. ${ }^{40}$

Fourth, sea levels are rising. Between 1901 and 2010, global average sea level rose about 0.19 meters,

34 ibid.

352014 IPCC Synthesis Report (n 12) 41.

36 ibid.

37 Sunke Schmidtko, Lothar Stramma and Martin Visbeck, 'Decline in global oceanic oxygen content during the past five decades' (2017) 542 Nature 335335.

382014 IPCC Synthesis Report (n 12) 53, fig 1.12.

39 Schmidtko, Stramma and Visbeck (n 37) 335; Lothar Stramma et al, 'Expansion of oxygen minimum zones may reduce available habitat for tropical pelagic fishes' (2011) 2 Nature Climate Change 33 33-37; Robert J Diaz and Rutger Rosenberg, 'Spreading dead zones and consequences for marine ecosystems' (2008) 321 Science 926, 926-929; Raquel Vaquer-Sunyer and Carlos M Duarte, 'Thresholds of hypoxia for marine biodiversity' (2008) 105 PNAS 15452 15452-15457.

40 'Hypoxia occurs when DO [dissolved oxygen] falls below $\leq 2 \mathrm{ml}$ of $\mathrm{O}_{2} /$ liter, at which point benthic fauna show aberrant behavior-for example, abandoning burrows for exposure at the sediment-water interface, culminating in mass mortality when DO declines below $0.5 \mathrm{ml}$ of $\mathrm{O}_{2} /$ liter.' Diaz and Rosenberg (n 39) 926. Research indicates that the number of coastal sites where hypoxia has been reported has increased with an exponential growth rate of $5.54 \%$ [per year] over time.' Vaquer-Sunyer and Duarte (n 39) 15452. 
and the rate of sea level rise is increasing. ${ }^{41}$ Both ocean warming and glacier melting contribute to sea level rise ${ }^{42}$ as noted above, salinity also matters. The IPCC projects that sea level rise will accelerate throughout the 21st century, although the increase will not be uniform in all locations. ${ }^{43}$

Sea level rise is primarily a threat to coastal ecosystems and settlements, although coastal inundation is currently less of a threat than worsening storm surge. As the IPCC noted in 2014, "[i]t is likely that extreme sea levels (for example, as experienced in storm surges) have increased since 1970, being mainly the result of mean sea level rise. ${ }^{44}$

Finally, absorbed carbon dioxide is reacting chemically in the ocean to reduce the ocean's $\mathrm{pH}$, a phenomenon known as ocean acidification. According to the IPCC, "[s]ince the beginning of the industrial era, oceanic uptake of $\mathrm{CO}_{2}$ has resulted in acidification of the ocean; the $\mathrm{pH}$ of ocean surface water has decreased by o.1 (high confidence),' corresponding to a $26 \%$ increase in acidity, measured as hydrogen ion concentration. ${ }^{45}$ Ocean acidification will continue into the 21st century, and under the worst scenarios ('business as usual') could decrease the ocean's $\mathrm{pH}$ by another 0.30 to 0.32 units, an increase in acidity of 100-109 percent. ${ }^{46}$

Ocean acidification most directly affects marine creatures with shells, ${ }^{47}$ but pervasive changes to ocean $\mathrm{pH}$ can affect other species, as well. For example, fisheries in Alaska-and the communities who depend upon those fisheries - are at significant risk because of ocean acidification. ${ }^{48}$ Ocean acidification also has more subtle effects, such as interfering with chemical signaling among ocean species. ${ }^{49}$ According to some scientists, ocean acidification threatens a mass extinction event, and the current rate of (mainly fossil fuel) $\mathrm{CO}_{2}$ release stands out as capable of driving a combination and magnitude of geochemical changes potentially unparalleled in the last $\sim 300$ [million years] of Earth history, raising the possibility that we are entering an unknown territory of marine ecosystem change. ${ }^{50}$

\section{Implications for Marine Ecosystems and Human Well-Being}

As a result of all of these impacts, marine ecosystems around the globe are already being affected by climate change and ocean acidification. ${ }^{51}$ The impacts most relevant to human well-being and to law include changes in marine species richness, changes in regional species abundance, impacts on large non-fish marine species (such as marine mammals), and changes in fishery yields. ${ }^{52}$

Importantly, many of these impacts are synergistic. For example, the 'changes in temperature and ocean carbonate chemistry are considered two of the greatest threats to marine biodiversity, leading to changes in the physiological performance of individual organisms, which will in turn alter biotic interactions, community structure, and ecosystem functioning. ${ }^{53}$ However, ocean warming and ocean acidification also produce complexly synergistic effects more intensely in combination than alone. ${ }^{54}$

In September 2015, a World Wildlife Fund study concluded that the individual and synergistic impacts of human activities affecting the ocean-climate change, ocean acidification, habitat destruction, and overfishing - had led to a $49 \%$ decline in marine species populations between 1970 and 2012. ${ }^{55}$ Similarly, the International Union for the Conservation of Nature (IUCN) has noted that ' $[0]$ ther non-climate human stressors such as fishing and pollution will interact with climate-induced changes in

\footnotetext{
2014 IPCC Synthesis Report (n 12) 42.

ibid.

3 ibid 62.

4 ibid 53.

5 ibid 41.

6 ibid 62.

7 ibid 51.

48 JT Mathisa et al, 'Ocean acidification risk assessment for Alaska's fishery sector' (2015) 136 Progress in Oceanography 71 71-91.

49 Tristram D Wyatt, Jörg D Hardege and John Terschak, 'Ocean acidification foils chemical signals' (2014) 346 Science 176176.

50 Bärbel Hönisch et al, 'The Geological Record of Ocean Acidification' (2012) 335 Science 10581062.

512014 IPCC Synthesis Report (n 12) 50 fig 1.11(a).

52 ibid 52, fig 1.12.

53 Ben P Harvey, Dylan Gwynn-Jones and Pippa J Moore, 'Metaanalysis reveals complex marine biological responsesto the interactive effects of ocean acidification and warming' (2013) 3(4) Ecology \& Evolution 1016, 1016 (citing S Doney, V Fabry, R Feely, and J Kleypas, 'Ocean acidification: the other $\mathrm{CO}_{2}$ problem' (2009) 1 Annu Rev Mar Sci 169 169-192; J Kleypas, R Buddemeier, D Archer, J Gattuso, C Langdon, and B Opdyke, 'Geochemical consequences of increased atmospheric carbon dioxide on coral reefs' (1999) 284 Science 118 118-120).

54 ibid 1026.

55 Jess Colarossi, 'Climate Change and Overfishing Are Driving The World's Oceans To The "Brink Of Collapse' (Think Progress 18 September 2015) <https://thinkprogress.org/climate-change-and -overfishing-are-driving-the-worlds-oceans-to-the-brink-of -collapse-2d095e127640> accessed 17 July 2017.
} 
fish populations, increasing the sensitivity of marine fishes to climate stressors. ${ }^{56}$

Changes to ocean temperatures, $\mathrm{pH}$, and species assemblages could well eliminate commercial marine fishing and drastically interfere with marine aquaculture as well, threatening human food security worldwide. ${ }^{57}$ In addition, the oceans supply about $50-85 \%$ of atmospheric oxygen, mostly through the photosynthetic activity of small plants known as phytoplankton. ${ }^{58}$ Too much disruption of ocean chemistry and biology, therefore, could fundamentally change all life on Earth. ${ }^{59}$

\section{Human Marine Activities as Contributors to Climate Change}

Human activities in the ocean also exacerbate climate change. Marine shipping is one obvious example. 'Since 1997, the International Maritime Organization ('IMO') has been developing rules concerning the reduction of the international shipping sector's greenhouse gas emissions within its wider role of reducing all forms of ship-sourced pollution. ${ }^{\prime 60}$ Offshore oil and gas development raises similar climate change concerns. $^{61}$

Marine fishing would at first blush seem to be a problem unrelated to climate change. However, marine overfishing can also accelerate climate change, much as deforestation can. Research published in September 2015 indicates that overfishing of large predators in the ocean, such as sharks, allows their normal prey to multiply and decimate marine plants (seaweeds, seagrasses) - the marine vegetation that sequesters carbon dioxide from the atmosphere. ${ }^{62}$ These marine plants, known as 'blue carbon ecosystems,' sequester carbon dioxide 40 times faster than land plants (including tropical rainforests), and they can keep that carbon dioxide sequestered on millennial time scales. ${ }^{63}$ As such, preservation and possibly expansion of these marine ecosystems should be a climate change mitigation strategy.

\section{A Marine-Centric View of Common but Differentiated Responsibilities in International Law}

\section{Introduction to Common but Differentiated Responsibilities (CBDR)}

Common but Differentiated Responsibilities (CBDR) is a well-established concept in international environmental law. CBDR seeks to achieve equity in international relations ${ }^{64}$ by balancing nations' responsibilities to redress global issues with their right to develop. ${ }^{65}$ The principle of CBDR thus has two 'core elements': (1) the common responsibility of nations to protect 'the environment, or parts of it, at the national, regional and global levels'; and (2) the necessity of taking into account each nation's particular circumstances, 'particularly each State's contribution to the evolution of a particular problem and its ability to prevent, reduce and control the threat. ${ }^{, 66}$

For CBDR to apply, however, environmental issues must be 'common.' In this context, 'common' refers
562016 IUCN Ocean Warming Report, (n 12) 240.

57 See generally Robin Kundis Craig, 'Re-Tooling Marine Food Supply Resilience in a Climate Change Era: Some Needed Reforms' (2015) 38 Seattle U L Rev 1189-1235 (discussing the growing threat to world food security from the overall synergistic impacts on the ocean); see also World Watch Institute, 'Overfishing and Climate Change, Combined, Intensify Ocean Threats' (World Watch Institute 18 August 2015) < https://www.worldwatch .org/overfishing-and-climate-change-combined-intensify-ocean -threats> accessed 17 July 2017.

58 EarthSky, 'How much do oceans add to world's oxygen?' (Earth Science Wire 8 June 2015) <http://earthsky.org/earth/how-much -do-oceans-add-to-worlds-oxygen> accessed 17 July 2017.

59 See generally Peter C Ward, Under a Green Sky: Global Warming, the Mass Extinctions of the Past, and What They Can Tell Us About Our Future (Smithsonian Books 2007).

60 Stathis N Palassis, 'The IMO's Climate Change Challenge: Application of the Principle of Common but Differentiated Responsibilities and Respective Capabilities' (2014) 6 Wash \& Lee J Energy, Climate \& Envt 160 162-63.
61 Eg, Tim Donaghy, 'The Climate Change Costs of Offshore Drilling' (Greenpeace.org, 9 June 2016) <http://www.greenpeace .org/usa/research/climate-change-costs-offshore-oil-drilling > accessed 17 July 2017.

62 TB Atwood et al, 'Predators help protect carbon stocks in blue carbon ecosystems' (2015) 5 Nature Climate Change 10381042.

63 Sarah Sedghi, 'Shark culling and overfishing may be contributing to climate change' (ABC News Australia 29 September 2015) $<$ http://www.abc.net.au/news/2015-09-29/sharks-and-other -predators-help-prevent-climate-change/6813042> accessed 17 July 2017.

64 Centre for International Sustainable Development Law, 'The Principle of Common But Differentiated Responsibilities: Origin and Scope' (2002) [hereinafter 2002 CISDL CBDR Briefing] <http://cisdl .org/public/docs/news/brief_common.pdf> accessed 17 July 2017

65 Rowena Maguire, 'The Role of Common but Differentiated Responsibility in the 2020 Climate Regime: Evolving a New Understanding of Differential Commitments' (2013) 7 Carbon \& Climate L Rev 260260.

662002 CISDL CBDR Briefing (n 64) 1. 
to collective or common interests, ${ }^{67}$ while 'common responsibilities' refer to 'the shared obligations of two or more States towards the protection of a particular environmental resource. ${ }^{.68}$ 'Differentiated' responsibilities, in turn, '[aim] to promote substantive equality between developing and developed States within a regime, rather than mere formal equality. ${ }^{169}$ Thus, rather than subjecting all party States to the exact same obligations, CBDR regimes assign responsibilities based on a range of factors, including a nation's level of development and its contribution to the problem being addressed. ${ }^{70}$

\section{CBDR in International Climate Change Law}

Formal international legal responses to climate change best date from the UNFCCC, which was introduced at the Rio Earth Summit in 1992. ${ }^{71}$ This Convention has been ratified by 195 countries, and it came into force on 21 March $1994 .^{72}$ The UNFCCC has two central frameworks for addressing climate change. First, it frames climate change as an environmental pollution problem. ${ }^{73}$ Second, it links climate change to sustainable development, acknowledging that developing nations still need to deal with social and economic issues such as poverty ${ }^{74}$

CBDR is one of the UNFCCC's central principles. The Convention's 'ultimate objective' 'is to achieve . .. stabilization of greenhouse gas concentrations in the atmosphere at a level that would prevent danger-

67 Maguire (n 65) 264.

682002 CISDL CBDR Briefing (n 64) 1.

69 ibid, See also Pieter Pauw et al, 'Different Perspectives on Differentiated Responsibilities: A State-of-the-Art Review of the Notion of Common but Differentiated Responsibilities in International Negotiations' (Discussion Paper, 2014) <https://www.die-gdi.de/ uploads/media/DP_6.2014..pdf $>$ accessed 17 July.

70 'Differentiated' obligations must be considered on two bases. Firstly, considerations of the level of economic development in a particular nation. And secondly the differing contributions to global environmental degradation. Maguire (n 65) 264; see also 2002 CISDL CBDR Briefing (n 64) 2 (listing other factors)

71 UNFCCC (n 8)

72 ibid.

73 Pauw et al (n 69) 8

74 ibid (citation omitted).

75 United Nations Framework Convention on Climate Change (adopted 9 May 1992, entered into force 21 Mach 1994) 1771 UNTS 107 ous anthropogenic interference with the climate system. ${ }^{, 75}$ However, it seeks to achieve that common objective through differentiated responsibilities, dividing the parties into developed States-the industrialised nations that have contributed the most greenhouse gases to the atmosphere-and developing States, whose contributions to climate change to date have generally been far more limited. ${ }^{76}$ Under Article 3(1):

The Parties should protect the climate system for the benefit of present and future generations of human kind on the basis of equity and in accordance with their common but differentiated responsibilities and respective capabilities. Accordingly, the developed country Parties should take the lead in combating climate change and the adverse effects thereof. ${ }^{77}$

As a result, the UNFCCC imposes primary obligations for reducing greenhouse gas emissions on the Annex I developed nations, with financial responsibility falling on an overlapping list of Annex II developed nations. ${ }^{78}$ Developing nations do take on obligations - some of which, as will be seen, are important to the ocean — but their duties to reduce their greenhouse gas emissions have so far been extremely limited.

The Kyoto Protocol reified a very 'rough cut' CBDR regime by creating greenhouse gas reduction commitments for developed (Annex I) nations only. ${ }^{79}$ In 2012, the Conference of the Parties in the Bali Action Plan continued to emphasize that 'Parties' efforts should be undertaken on the basis of equity and
76 As the Convention web site explains, 'The idea is that, as they are the source of most past and current greenhouse gas emissions, industrialised countries are expected to do the most to cut emissions on home ground. They are called Annex I countries and belong to the Organization for Economic Cooperation and Development (OECD). They include 12 countries with 'economies in transition' from Central and Eastern Europe. Annex I countries were expected by the year 2000 to reduce emissions to 1990 levels.' UNFCCC (n 8).

77 UNFCCC (n 75) art 3(1).

78 ibid art 4(2).

79 Maguire (n 65) 264-65. 'The Kyoto Protocol of 1997 (which entered into force in 2005) reinforced the clear divide between Annex I (generally the developed countries) and Non-Annex I parties (the developing countries). Most of the Annex I parties to the convention agreed on legally binding targets to limit or reduce their greenhouse gas emissions, as listed under Annex B in the Kyoto Protocol. Non-Annex I parties also ratified the protocol, but it does not include binding targets for them to limit or reduce their emissions. In practice, this means that emissions of developing countries are allowed to grow in accordance with their development needs.' Pauw et al (n 69) 9. 
common but differentiated responsibilities and respective capabilities .... ${ }^{80}$

The most recent Paris Accord (December 2015) again acknowledges 'the specific needs and concerns of developing country Parties arising from the impact of the implementation of response measures ${ }^{81}$ but focuses on 'individual nationally determined contributions' (INDCs)—each Party's self-determined emissions reductions and climate change adaptation goals, ${ }^{82}$ which are supposed to be in place by 2020 , when the agreement takes effect. ${ }^{83}$ In some respects, therefore, the Paris Accord has reduced the UNFCCC's sharp dichotomy with respect to CBDR. ${ }^{84} \mathrm{How}^{-}$ ever, the differences between Annex I and non-Annex I countries continue; for example, the Paris Accord emphasizes the importance of financing and technology transfer for developing nations ${ }^{85}$ while adding new loss and damage provisions for them. ${ }^{86}$ As the United Nations has summarised, " $t$ the principle of common but differentiated responsibilities is reflected in this Agreement. ${ }^{87}$

\section{An Ocean-Centric View of CBDR in the Anthropocene}

To date, the application of CBDR to climate change has focused almost exclusively on two factors: (1) nations' actual greenhouse gas emissions; and (2) each nation's status as 'developed' or 'developing. ${ }^{88}$ To be sure, assessing CBDR using these two factors is already both scientifically and politically complex enough to engender repeated and often heated international negotiations. ${ }^{89}$ Nevertheless, this CBDR calculus frames a nation's UNFCCC-relevant environmental contribution solely in terms of the carbonequivalents that it emits into the atmosphere, ignoring any disproportionate synergistic environmental impacts that a particular nation might be imposing on the rest of the world. The potential infirmities of this assessment framework are already evident in the fact that the international community has promoted additional programs to protect carbon sinks, such as the Reducing Emissions from Deforestation and Degradation (REDD) program and its goal of reducing deforestation. ${ }^{90}$

The connection between humans' ocean activities and climate change is already challenging the UNFCCC's concept of CBDR. For example, with respect to marine shipping, the IMO has long followed the principle that all ocean-going ships of similar size and design should be subject to the same environmental standards-ie, that CBDR is not relevant. ${ }^{91}$ Stathis Palassis has chronicled the growing collision between climate change CBDR as envisioned under the UNFCCC and the IMO's attempts to control greenhouse gas emissions from ships, concluding that that the twin goals of differentiation and uniformity do not sit comfortably together. ${ }^{92}$

Global marine fishing and ocean acidification, however, have generally been exempted from the climate change CBDR discussion, despite their direct and indirect connections to climate change. A marine-centric view of climate change regulation would
80 Conference of the Parties, United Nations Framework Convention on Climate Change, 'Report of the Conference of the Parties on its eighteenth session, held in Doha from 26 November to 8 December 2012: Addendum: Part Two: Action taken by the Conference of the Parties at its eighteenth session' (28 February 2013) 3 व 2 $<$ http://unfccc.int/resource/docs/2012/cop18/eng/08a01.pdf\#page $=3>$ accessed 17 July.

81 ibid 2.

82 ibid 3-4

83 United Nations, 'The Paris Agreement: Frequently Asked Questions' (UN Sustainable Development Blog 12 September 2016) <https://www.un.org/sustainabledevelopment/blog/2016/09/the -paris-agreement-faqs/> accessed 17 July 2017.

84 Pauw et al (n 69) 11.

85 21st Conference of the Parties, United Nations Framework Convention on Climate Change, Adoption of the Paris Agreement 8-10 (12 December 2015) [hereinafter 2015 Paris Agreement] <http://unfccc.int/resource/docs/2015/cop21/eng/l09r01.pdf> accessed 17 July.

86 ibid 10-11
87 United Nations (n 83).

88 'The principle of CDR now embodied in the UNFCCC means that two factors determine a nation's obligations concerning climate change. The first factor is a particular nation's contribution to climate change through GHG emissions; the second is its economic and technological capacity to reduce emissions. The CDR is primarily backward-looking, as it focuses on past contributions to existing stocks of emissions and lays out responsibilities intended to have remedial effects.' MJ Bortscheller, 'Equitable but Ineffective: How the Principle of Common but Differentiated Responsibilities Hobbles the Global Fight Against Climate Change' (2010) 10(2) Sustainable Development L \& Pol'y 4950.

89 The UNFCCC web page provides a comprehensive history of the formal negotiations and Conferences of the Parties that have occurred under the Convention. United Nations Framework Convention on Climate Change, 'Home Page' <http://unfccc.int/ 2860.php> accessed 17 July 2017.

90 UN-REDD Programme, 'About the UN-REDD Programme' <http://www.un-redd.org> accessed 17 July 2017.

91 Palassis (n 60) 163.

92 ibid 195. 
take nations' contributions to each into account when assessing CBDR.

\section{a. Marine Fishing and CBDR}

As is true of terrestrial deforestation, loss of marine plant ecosystems (as noted, often referred to as 'blue carbon' ecosystems) releases carbon dioxide and reduces the world's carbon sinks. Indeed, losing one percent of marine plant ecosystems is the equivalent of releasing 460 million tonnes of carbon per year. ${ }^{93}$

Thus, reducing the loss of these ecosystems is directly relevant to mitigating climate change and should be part of the UNFCCC's climate change CBDR. As noted, moreover, marine fishing contributes to climate change by reducing these ecosystems and hence provides one measure of how a nation is directly impacting climate change.

Beyond climate change mitigation, however, accounting for marine fishing also implements other duties under the UNFCCC. UNFCCC Section 4(1) imposes a number of duties on all Parties, 'taking into account their common but differentiated responsibilities and their specific national and regional development priorities, objectives and circumstances,' and three of these duties are particularly relevant to the ocean. First, all Parties agree to '[p]romote sustainable management, and promote and cooperate in the conservation and enhancement, as appropriate, of sinks and reservoirs of all greenhouse gases not controlled by the Montreal Protocol,' including explicitly the ocean and marine and coastal ecosystems. ${ }^{94}$ Second, all Parties explicitly agree to '[c]ooperate in preparing for adaptation to the impacts of climate change,' including explicitly through coastal management. ${ }^{95}$ Finally, Parties agree to ' $\mathrm{t}$ ] ake climate change considerations into account, to the extent feasible, in their relevant social, economic and environmental policies and actions. ${ }^{\prime 96}$ As such, and given marine fishing's synergistic impacts with climate change in the ocean, it makes sense to include a nation's marine fishing impact as part of the Paris Accord's INDCs.

\section{Carbon Dioxide Emissions, Ocean Acidification, and CBDR}

While carbon dioxide emissions are relevant to both climate change and ocean acidification, the impacts of these two phenomena are nevertheless both dif- ferent and synergistic. Climate change's impacts on the oceans are largely physical-increasing temperatures and changing currents-producing the suite of follow-on impacts discussed above. Ocean acidification, in turn, produces a fundamental change in ocean chemistry. ${ }^{97}$

Nevertheless, these processes can interact and reinforce each other, creating positive feedback loops that accelerate the degradation of the oceans, the loss of marine biodiversity, and the progress of climate change. For example, a warming ocean can absorb less carbon dioxide, and hence the increasing impacts of climate change on the ocean are undermining the ocean's ability to mitigate climate change's impacts on the rest of the world. Overall, 'the open ocean is projected to absorb a decreasing fraction of anthropogenic $\mathrm{CO}_{2}$ emissions as those emissions increase,' leaving $30 \%$ to $69 \%$ of 21 st-century carbon dioxide emissions in the atmosphere, depending on future emissions scenario. ${ }^{98}$ At the same time, climate change-driven changes to ocean currents cause increased upwellings of nutrients from the ocean floor, which in turn generally exacerbate ocean acidification. $^{99}$

The benefit of legally linking climate change and ocean acidification is perhaps obvious: ocean acidification is caused entirely, and climate change primarily, by anthropogenic emissions of carbon dioxide. ${ }^{100}$ Therefore, it makes eminent sense to couple the international regulatory response to these two environmental phenomena under the UNFCCC. ${ }^{101}$

\footnotetext{
93 Sedghi (n 63).

94 UNFCCC (n 75) art 4(1)(d).

95 ibid art 4(1)(e).

96 ibid art 4(1)(f).

97 JP Gattuso et al, 'Contrasting futures for ocean and society from difference $\mathrm{CO}_{2}$ emissions scenarios' (2015) 349(6243) Science 45 45.

98 ibid aac4722-5.

99 Northwest Association of Networked Ocean Observing Systems (NANOOS), 'Ocean Acidification: What Is Ocean Acidification?' <http://www.nanoos.org/education/learning_tools/oa/ocean _acidification.php> accessed 17 July 2017; Xochitl Rojas-Rochas, 'Worsening ocean acidification threatens Alaska fisheries' (Science Insider Daily News 29 July 2014) < http://news .sciencemag.org/climate/2014/07/worsening-ocean-acidification -threatens-alaska-fisheries> accessed 17 July 2017.

100 Ellycia Harrould-Kolieb and Dorothée Herr, 'Ocean acidification and climate change: Synergies and challenges of addressing both under the UNFCCC' (2011) Climate Policy 13 . <http://arnmbr .org/content/images/uploads/Ocean_Acidification_Climate _Change_UNFCCC.pdf $>$ accessed 17 July.
}

101 ibid 6. 


\section{Conclusion}

To date, the UNFCCC CBDR calculus has done very little even to consider ocean acidification, ${ }^{102}$ while including fisheries within this framework appears to be on no one's agenda. However, both considerations are readily workable, and their incorporation would reveal some nations to be 'triple threats' while most of the rest are more nuanced contributors to increasingly synergistic problems in the atmospheric/oceanic global commons.

Ocean acidification is arguably the easier of the two to incorporate into the UNFCCC framework. However, the Kyoto Protocol and its successors allow climate change mitigation efforts to apply to four greenhouse gases and two groups of other gases, whereas only carbon dioxide emissions are relevant to ocean acidification. ${ }^{103}$ As a result, advocates seeking to incorporate ocean acidification into the UNFCCC have argued that future UNFCCC protocols and implementing agreements should distinguish between carbon dioxide and other relevant greenhouse gas emissions to more effectively acknowledge the problem of ocean acidification. ${ }^{104}$

Some have suggested that the UNFCCC be modified to focus solely on carbon dioxide, leaving the other greenhouse gases to a different treaty. ${ }^{105}$ However, the dual role of carbon dioxide in causing both climate change and ocean acidification could instead become a means for more finely differentiating

\footnotetext{
102 ibid 4.

103 ibid 5. The four greenhouse gases are carbon dioxide, methane, nitrous oxide, and sulfur hexafluoride; the two other groups are hydrofluorocarbons and perfluorocarbons.

104 ibid.

105 ibid

106 US Environmental Protection Agency, 'Global Anthropogenic Non- $\mathrm{CO}_{2}$ Greenhouse Gas Emissions: 1990-2030' (2012) Appendix A-1: Combined Methane, Nitrous Oxide, and High GWP Emissions by Country <http://www3.epa.gov/climatechange/ EPAactivities/economics/nonco2projections.html> (webpage no longer visible).

107 Union of Concerned Scientists, 'Each Country's Share of $\mathrm{CO}_{2}$ Emissions' (Union of Concerned Scientists: Global Warming Science, 18 November 2014) <http://www.ucsusa.org/global _warming/science_and_impacts/science/each-countrys-share-of -co2.html\#.WdXtLdhpGUl> accessed 17 July 2017.

108 Food and Agriculture Organization of the United Nations, 'Fisheries and Aquaculture Department Publications' <http://www.fao .org/fishery/publications/sofia/en> accessed 17 July 2017.

109 Food and Agriculture Organization of the United Nations, 'The State of World Fisheries and Aquaculture: Contributing to Food Security and Nutrition for All' (Report, 2016) 11 tbl $2<$ http:// www.fao.org/3/a-i5555e.pdf $>$ accessed 17 July 2017.
}

among nations' climate change CBDR. For example, Nigeria emits more non-carbon dioxide greenhouse gases than either Japan or Germany, ${ }^{106}$ but Japan and Germany are ranked fifth and sixth, respectively, in terms of nations' overall carbon dioxide emissions, while Nigeria doesn't even make the list of top 20 emitters. ${ }^{107}$ A climate change CBDR calculus that considered ocean acidification would thus hold Japan and Germany doubly (climate change and ocean acidification) responsible because of these countries' significant carbon dioxide emissions, while Nigeria's CBDR would be based solely on its contribution to climate change.

Including marine fishing effort into nations' climate change CBDR would need to be more nuanced, especially at first, given the more attenuated contribution of marine fishing to climate change and its development connection to individual nations' food security. As a first step, as Party nations submit and modify their INDCs under the Paris Accord, those national commitments could include fishing policies and reflect the synergistic impacts of climate change, ocean acidification, and overfishing.

Nevertheless, including a nation's marine fishing effort into its climate change CBDR is relatively easily done because information about each nation's contribution is readily available: Every two years the FAO publishes The State of World Fisheries and Aquaculture, summarising nations' individual fishing efforts. ${ }^{108}$ Adding marine fishing to the climate change CBDR calculus would significantly differentiate certain nations. The FAO's latest (2016) report lists the top 25 countries for marine wild capture fisheries, based on 2013 and 2014 catch data, as (in descending order): China; Indonesia; United States; Russian Federation; Japan; Peru; India; Viet Nam; Myanmar; Norway; Chile; Philippines; Republic of Korea; Thailand; Malaysia; Mexico; Morocco; Spain; Iceland; Taiwan Province of China; Canada; Argentina; United Kingdom; Denmark; and Ecuador. ${ }^{109}$ Most importantly for CDBR calculations, this is an overlapping but overall very different list of 'top nations' than usually arises in the climate change context. It also underscores the fact that the UNFCCC's 'rough cut' of developing nations elides some important economic and environmental impact differences among the non-Annex I nations, especially with respect to China and India.

An ocean-centric climate change CBDR reveals that some nations (China, United States, India, Japan, 
Mexico, Russia) are multiple contributors to the synergies among climate change, ocean acidification, and overfishing, while others that often escape climate change blame (Myanmar, Malaysia) — and may even be viewed as climate change victims ${ }^{110}$ - are in fact contributing significantly to those more comprehensive global interactions and complexities. Thus, incorporating marine fishing and ocean acidification into the UNFCCC's climate change CBDR would help to meaningfully differentiate nations while simultaneously better reflecting the full spectrum of responsibilities that nations have agreed to address under that Convention.

110 Eg, Amantha Perera, 'Myanmar Wakes Up to Climate Change,' (Inter Press Service News Agency, 6 May 2014) <http://www .ipsnews.net/2014/05/myanmar-wakes-climate-change/> accessed 17 July 2017. 